\title{
Reviewing SEBAL input parameters for assessing evapotranspiration and water productivity for the Low-Middle São Francisco River basin, Brazil Part A: Calibration and validation
}

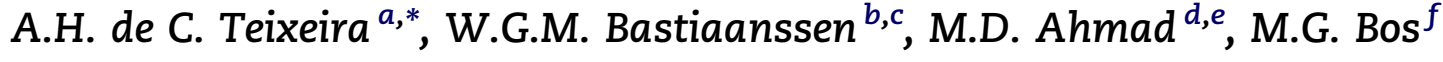 \\ ${ }^{a}$ Embrapa Semi-Árido, P.O. Box 23, 56302-970 Petrolina, PE, Brazil \\ ${ }^{\mathrm{b}}$ WaterWatch, Generaal Foulkesweg 28, 6703 BS, Wageningen, The Netherlands \\ ${ }^{c}$ Delft University of Technology, Stevinweg 1, 2600 GA, Delft, The Netherlands \\ ${ }^{\mathrm{d}}$ Formerly with International Water Management Institute, P.O. Box 2075, Colombo, Sri Lanka \\ ${ }^{e}$ Currently at CSIRO Land and Water, GPO Box 1966, Canberra act 2601, Australia \\ ${ }^{\mathrm{f}}$ Formerly with International Institute for Geo-Information Science and Earth Observations, P.O. Box 6, 7500 AA, \\ Enschede, The Netherlands
}

\section{A R T I C L E I N F O}

Article history:

Received 13 May 2008

Received in revised form

3 September 2008

Accepted 24 September 2008

Keywords:

Latent heat flux

Sensible heat flux

Soil heat flux

Net radiation

Evaporative fraction

Actual evapotranspiration

\begin{abstract}
A B S T R A C T
There is a growing interest in quantifying regional scale actual evapotranspiration (ET) for water accounting and for water productivity assessments at river basin scale. Methods that provide point values fail to describe the situations at larger scales. Remote sensing measurements can be used at different spatial scales. This paper applies the theory of the Surface Energy Balance Algorithm for Land (SEBAL). SEBAL was originally derived for Egypt, Spain and Niger [Bastiaanssen, W.G.M., 1995. Regionalization of surface flux densities and moisture indicators in composite terrain: a remote sensing approach under clear skies in Mediterranean climates. Ph.D. dissertation, CIP Data Koninklijke Bibliotheek, Den Haag, The Netherlands. 273 pp.] and was calibrated and validated using ground measurements from four flux sites and from seven agro-meteorological stations in the semi-arid region of the Low-Middle São Francisco River basin, Brazil. Measured parameters included surface albedo, surface temperature, atmospheric and surface emissivity, soil heat flux, surface roughness, net radiation, air temperature gradients, sensible heat flux, latent heat flux, evaporative fraction, and photosynthetically active radiation. The daily ET was estimated (RMSE of $0.38 \mathrm{~mm} \mathrm{~d}^{-1}$ ) for mixed agricultural and natural ecosystems. The improved coefficients for the local conditions can now be used to study the impact of expanding irrigated agriculture on the regional water balance and to quantify the water productivity of irrigated horticulture that is the largest water consumer in the Brazilian semi-arid region. Both applications are described in an accompanying paper (Part B).
\end{abstract}

(C) 2008 Elsevier B.V. All rights reserved.

\footnotetext{
* Corresponding author. Tel.: +55 87 38621711; fax: +55 8738621744.

E-mail address: heribert@cpatsa.embrapa.br (A.H. de C. Teixeira). 0168-1923/\$ - see front matter (C) 2008 Elsevier B.V. All rights reserved. doi:10.1016/j.agrformet.2008.09.016
} 
1.

\section{Introduction}

Irrigated agriculture in the semi-arid region of the São Francisco River basin (North-east Brazil) constitutes an important activity for livelihood of rural communities. The potential for fruit production in this region has been confirmed by the continuous expansion of irrigated land. Vineyards and mango orchards are the major crops. These land use changes affect the regional scale water balance.

Together with rainfall and runoff, the ET controls the availability of water at the Earth's surface (McCabe and Wood, 2006). The accurate determination of ET significantly reduces uncertainties in the water balance of a (sub-)basin (Cleugh et al., 2007), providing water managers with information on (i) water resources being consumed and thus not longer available for downstream users, and (ii) water productivity, i.e. the consumption of water in terms of biomass production per unit of water (e.g. Steduto et al., 2007).

Field scale ET measurements on vineyards, mango orchard and natural vegetation (caatinga) were done in the Low-Middle São Francisco River basin. Micro-meteorological methods were used providing point values for specific sites (Teixeira et al., 2007, 2008a,b). Direct extrapolations of data from individual flux sites to the regional scale can lead to biased estimates, because a few flux sites cannot provide a fair sample of a larger area (Wylie et al., 2003).

According to Nagler et al. (2005), species-level vegetation maps and species-specific algorithms would be needed for scaling tower-based ET data to larger areas. Species maps are difficult to construct even with high-resolution aerial photography. Pelgrum and Bastiaanssen (1996) confirmed this difficult with the use of field data from 13 flux towers in a heterogeneous landscape in central Spain with irrigated crops, rainfed crops and natural vegetation being insufficient, because the spatial variations of these latent heat fluxes are dictated by plant spacing, leaf area index, soil wetness, etc. Therefore, data from flux stations are only a first estimate of ET from contrasting ecosystems (Leuning et al., 2005).

Allen et al. (2007b) summarized a number of examples of remote sensing applications for irrigation management issues in the Western U.S. Bastiaanssen and Harshadeep (2005) reported a range of applications in Asia. The major advantage of remote sensing is that the ET at a large scale can be computed on pixel-to-pixels basis applying a consistent set of equations that utilize unique spectral radiances for each pixel.

The spatial and temporal distribution of ET can be mapped from remote sensing techniques without going through excessive ground truth data collection (e.g. Franks and Beven, 1999). According to Nagler et al. (2007), remotely sensed vegetation indices, obtained as a time series over a growing season, and micrometeorological data can be used to extrapolate plot level measurements of ET and water productivity over larger landscapes units. Another advantage of remote sensing is that ET is sampled over many fields growing the same crop or over natural bush land. In this way it is possible to determine true averages for a certain ecosystem or region (Tasumi and Allen, 2007).

Jackson et al. (1977) pioneered in Arizona with the determination of ET by thermal remote sensing data, using infrared thermometry in wheat. Choudhury (1989), Schmugge and Becker (1991), Kustas and Norman (1996), Bastiaansssen et al. (1998a), Bastiaanssen et al. (1999), Kustas et al. (2004), Courault et al., 2005 and Allen et al. (2007a) provided reviews of the progressive development of remote sensing algorithms for the estimation of ET during the last 20 years.

These reviews basically concluded that after these years of research, algorithms are sufficiently robust to be used for water management. One of these algorithms is the Surface Energy Balance Algorithm for Land (SEBAL). SEBAL has been applied to a variety of ecosystems (Bastiaansssen et al., 1998b; Bastiaanssen et al., 1999; Bastiaansssen et al., 2001; Bastiaanssen et al., 2002, 2005, 2008; Wang et al., 1998; Bastiaansssen, 2000; Farah and Bastiaanssen, 2001; Bastiaanssen and Bandara, 2001; Ahmad and Bastiaanssen, 2003; Bastianssen and Chandrapala, 2003; Chemin et al., 2004; Allen et al., 2005; ElMagd and Tanton, 2005; Akbari et al., 2007; Immerzeel et al., 2008).

SEBAL was introduced in the São Francisco River basin in 2000 (Bastiaansssen et al., 2001). This introduction has prompted Embrapa (Brazilian Agricultural Research Corporation) to use remote sensing for the up scaling of local water fluxes and water productivity in the basin. Although this algorithm was designed to calculate the energy balance at regional scale using a minimum of ground data, local parameterization of any remote sensing equations can improve the accuracy of the model (Duchemin et al., 2006).

This paper combined satellite data, field measurements of the surface radiation and energy balances and agro-meteorological stations to review the various SEBAL steps. During this process, the accuracy of individual empirical relationships, as well as the final validation of daily regional evapotranspiration, was investigated. The reviewed parameters were; surface albedo, surface temperature, surface and atmospheric emissivities, roughness length for momentum transport, net radiation, soil heat flux, air temperature gradient, sensible heat flux, latent heat flux, and photosynthetically active radiation. The relevant equations were adapted for the semiarid conditions in the Low-Middle São Francisco River basin, and then applied to each individual Landsat image.

\section{Material and methods}

\subsection{Brief outline of SEBAL major principles}

SEBAL requires spatially distributed, visible, near-infrared and thermal infrared data together with routine weather data. The algorithm computes net radiation $\left(R_{n}\right)$, sensible heat flux $(H)$ and soil heat flux $(G)$ for every pixel and the latent heat flux $(\lambda E)$ is acquired as a residual in energy balance equation. This is accomplished by first computing the regional surface radiation balance, followed by the regional surface energy balance. The schematic overview to convert spectral radiances into the net radiation using Landsat images is presented in Fig. 1.

The net shortwave radiation available at the earth surface depends on the incoming solar radiation $\left(R_{G}\right)$ and the surface albedo $\left(\alpha_{0}\right)$. The second parameter is calculated from satellitemeasured spectral radiances for each narrow band, followed by mathematical expressions for spectral integration and 


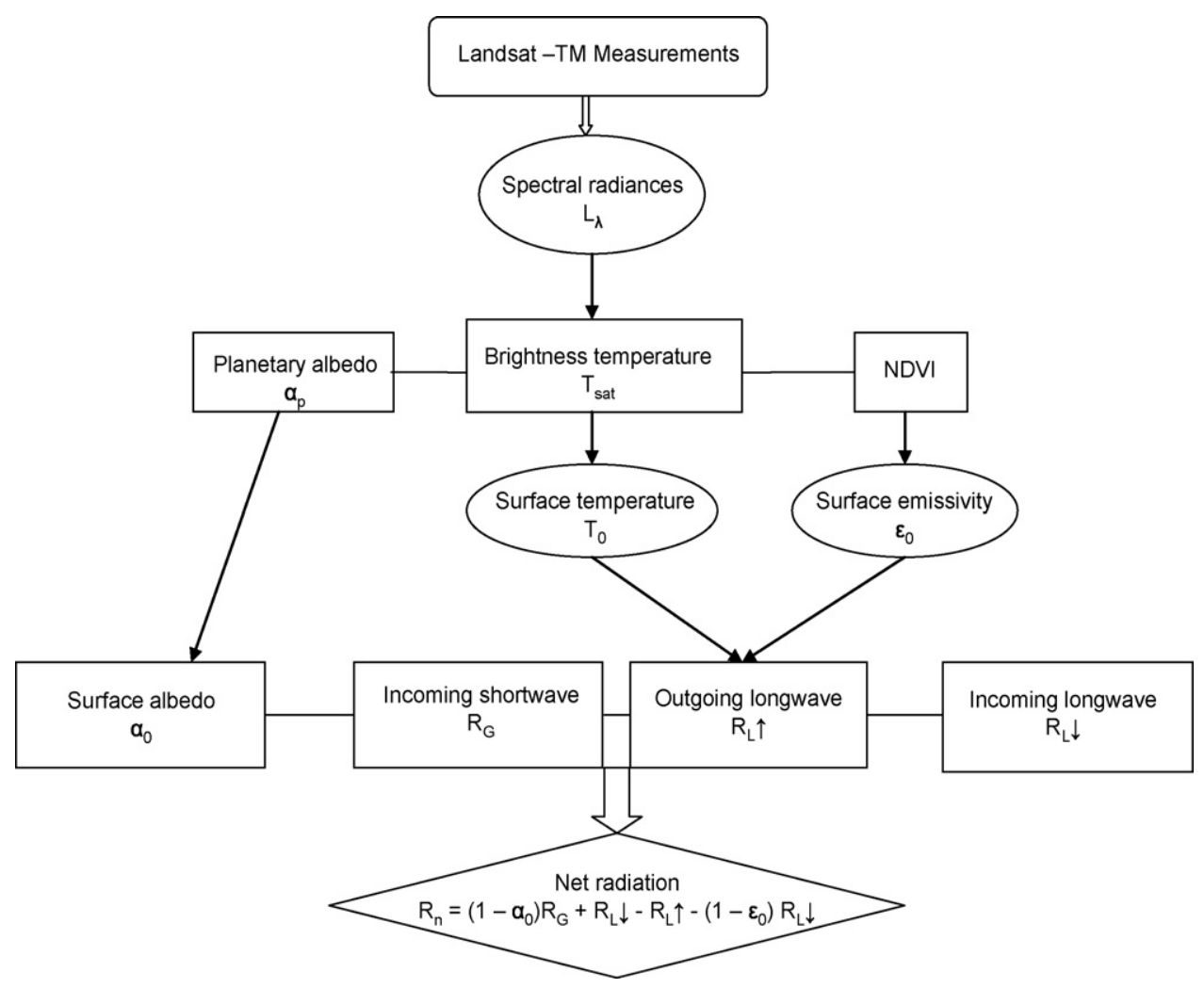

Fig. 1 - Schematic flowchart for the radiation balance.

atmospheric corrections. Regional $R_{G}$ in the present research was computed using interpolated measurements from pyranometers of seven agro-meteorological stations.

The incoming longwave radiation $\left(R_{\mathrm{L} \downarrow}\right)$ is calculated using the Stefan-Boltzmann equation with an empirically determined atmospheric emissivity $\left(\varepsilon_{\mathrm{a}}\right)$ and the field measurements of air temperature $(T)$. Outgoing longwave radiation $\left(R_{\mathrm{L} \uparrow}\right)$ is obtained using the Stefan-Boltzmann equation with an empirically determined surface emissivity $\left(\varepsilon_{0}\right)$ and surface temperature $\left(T_{0}\right)$ acquired by the satellite after atmospheric correction. The final term in radiation balance equation, $\left(1-\varepsilon_{0}\right) R_{\mathrm{L} \downarrow}$, represents the fraction of $R_{\mathrm{L} \downarrow}$ that is lost from the surface due to reflection. The local calibration of radiation balance terms is explained in detail in the next sections.

The second step of the SEBAL is to compute the soil $(G)$ and the sensible $(H)$ heat fluxes. The term $G$ is calculated by its relation with the $R_{n}$ by the ratio $G / R_{n}$. Most literature describes this last ratio to be a function leaf area index-LAI or Normalized Difference Vegetation Index-NDVI (e.g. Clothier et al., 1986; Choudhury, 1989). In contrast with these commonly accepted parameterizations, the role of $T_{0}$ in the physical description of heat diffusion is recognized in the present research by incorporating it into the parametric expression $G / R_{n}$. $H$ is obtained by near-surface temperature gradients (Fig. 2).

According to Fig. 2, the first value for friction velocity $\left(u^{*}\right)$ is computed for neutral stability, using data from agro-meteorological stations. The near-surface wind speed is converted to a value at the blending height, i.e. a height above the stations where the effects from the land surface roughness could be eliminated. A height of $200 \mathrm{~m}$ was considered $\left(u_{200}\right)$. The first estimate of $u^{*}$ is used-conjunctively with surface roughness estimates-to infer the first values of aerodynamic resistance $\left(r_{\mathrm{a}}\right)$. Corrections for atmosphere stability are obtained iteratively for each pixel ( $u_{*}$ _corr $)$, requiring a series of iterations to determine new values of $u_{*}{ }_{\text {_corr }}$ and $r_{a_{-} \text {corr }}$ before obtaining numerical stability.

SEBAL computes the near-surface vertical difference in air temperature $\Delta \mathrm{T}$ that governs the sensible heat flux by assuming the linear relationship between this gradient and surface temperature $\left(T_{0}\right)$ together with the coefficients of this relationship acquired following an internal calibration procedure (see also Allen et al., 2007a). This calibration is image and occasion dependent.

The algorithm uses two "anchor" pixels at which a value for $\mathrm{H}$ can be estimated on the basis of a priori knowledge (Fig. 2) of the fluxes over dryland (dry pixel) and wet terrain (cold pixel). For this study, the cold pixel and the hot pixel were considered on the plots of micro sprinkler irrigated mango orchard and natural vegetation, respectively, where the eddy covariance systems were installed. The sensible heat fluxes in these sites $\left(H_{\text {cold }}\right.$ and $H_{\text {hot }}$ ) were calculated applying the energy balance equation, and the annual generalized curves of the ratios $\mathrm{ET}_{\mathrm{a}} / \mathrm{ET}_{0}$ together with the $\mathrm{ET}_{0}$ for the anchor pixels at satellite overpass time. The reference evapotranspiration $\left(\mathrm{ET}_{0}\right)$ is the evapotranspiration rate from a reference surface, not short of water, which can be a hypothetical grass surface with specific characteristics (Allen et al., 1998). 


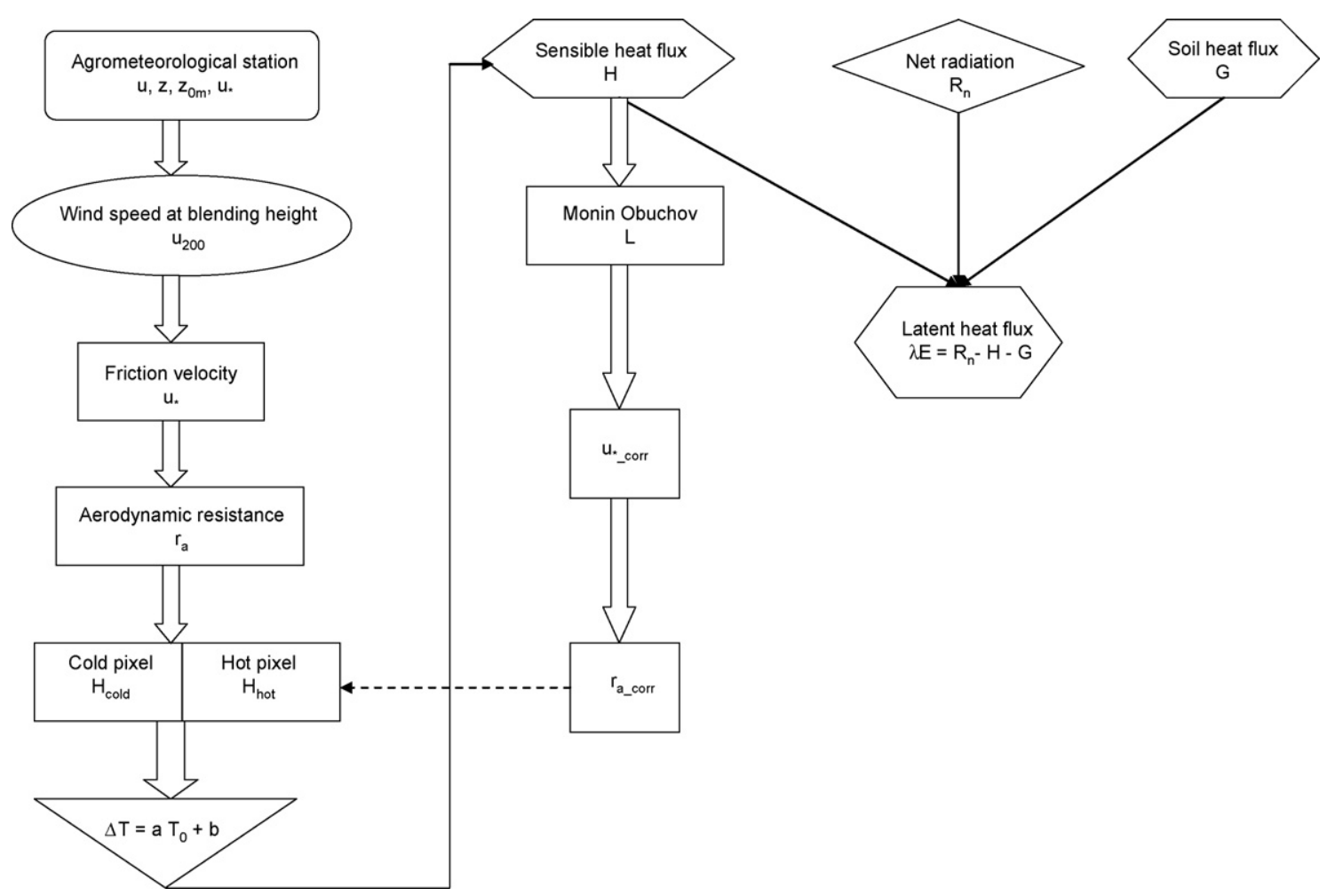

Fig. 2 - Schematic flowchart for the energy balance of the SEBAL algorithm.

The instantaneous estimation of the latent heat flux $(\lambda E)$ can be scaled to longer periods by using the evaporative fraction $\left[\lambda E /\left(R_{n}-G\right)\right]$ following Bastiaanssen et al. (2005) or applying the ratio $\mathrm{ET}_{\mathrm{a}} / \mathrm{ET}_{0}$ following Allen et al. (2007a). The essential SEBAL steps are elucidated in Allen et al. (2007a) and in Koloskov et al. (2007).

\subsection{Landsat measurements}

According to Fig. 1 the planetary albedo $\left(\alpha_{\mathrm{p}_{-} \mathrm{b}}\right)$ for each Landsat satellite band is:

$\alpha_{\mathrm{p} \_\mathrm{b}}=\frac{L_{\mathrm{b}} \pi d^{2}}{R_{\mathrm{a} \_\mathrm{b}} \cos \varphi}$

where $L_{b}$ is the spectral radiance for wavelengths of the band $b, d$ is the relative earth-sun distance; $R_{a \_b}$ is the mean solar exo-atmospheric irradiance (or atmospheric irradiance) for each band ( $\mathrm{W} \mathrm{m}^{-2} \mu \mathrm{m}^{-1}$ ) and $\varphi$ the solar zenith angle. The broadband planetary albedo $\left(\alpha_{\mathrm{p}}\right)$ is calculated as the total sum of the different narrow-band $\alpha_{\mathrm{p}_{\_} \mathrm{b}}$ values according to weights for each band $\left(w_{\mathrm{b}}\right)$.

$\alpha_{\mathrm{p}}=\sum w_{\mathrm{b}} \alpha_{\mathrm{p} \_\mathrm{b}}$

The weights for the different bands are computed as the ratio of the amount of incoming shortwave radiation from the sun in a particular band and the sum of incoming shortwave radiation for all the bands. The bands $1-5$ and 7 provide data for the visible and near infrared bands used for surface albedo calculations.
TM band 6 provides data for longwave (thermal) radiation. The spectral radiance in band $6\left(\mathrm{~L}_{6}\right)$ of Landsat can be converted into a radiation temperature applicable at the top of the atmosphere, the brightness temperature $\left(T_{\text {sat }}\right)$, by inversion of Plank's law in the 10.4-12.5 $\mu \mathrm{m}$ band width:

$\mathrm{T}_{\mathrm{sat}}=\frac{\mathrm{K}_{2}}{\ln \left(\mathrm{K}_{1} /\left(\mathrm{L}_{6}+1\right)\right)}$

where $L_{6}$ is the uncorrected thermal radiance from the land surface; and $K_{1}$ (607.76 and 666.09 for Landsat 5 and 7, respectively) and $K_{2}$ (1260.56 and 1282.71 for Landsat 5 and 7, respectively) are conversion coefficients (Markham and Barker, 1986; Landsat 7 Science Data User Data Handbook Chapter 11, 2002). One Landsat 7 and nine Landsat 5 images were used in this study (Table 1).

Table 1 - Satellite data over the period July 2001 to January 2007.

\begin{tabular}{lcl}
\hline Date & DOY & Satellite \\
\hline 10 September 2001 & 253 & Landsat 7 \\
04 October 2001 & 277 & Landsat 5 \\
06 July 2003 & 187 & Landsat 5 \\
24 September 2003 & 267 & Landsat 5 \\
12 October 2004 & 286 & Landsat 5 \\
14 November 2004 & 328 & Landsat 5 \\
15 October 2005 & 288 & Landsat 5 \\
16 November 2005 & 320 & Landsat 5 \\
30 July 2006 & 211 & Landsat 5 \\
22 January 2007 & 022 & Landsat 5 \\
\hline DOY-Day of the year. & & \\
\hline
\end{tabular}




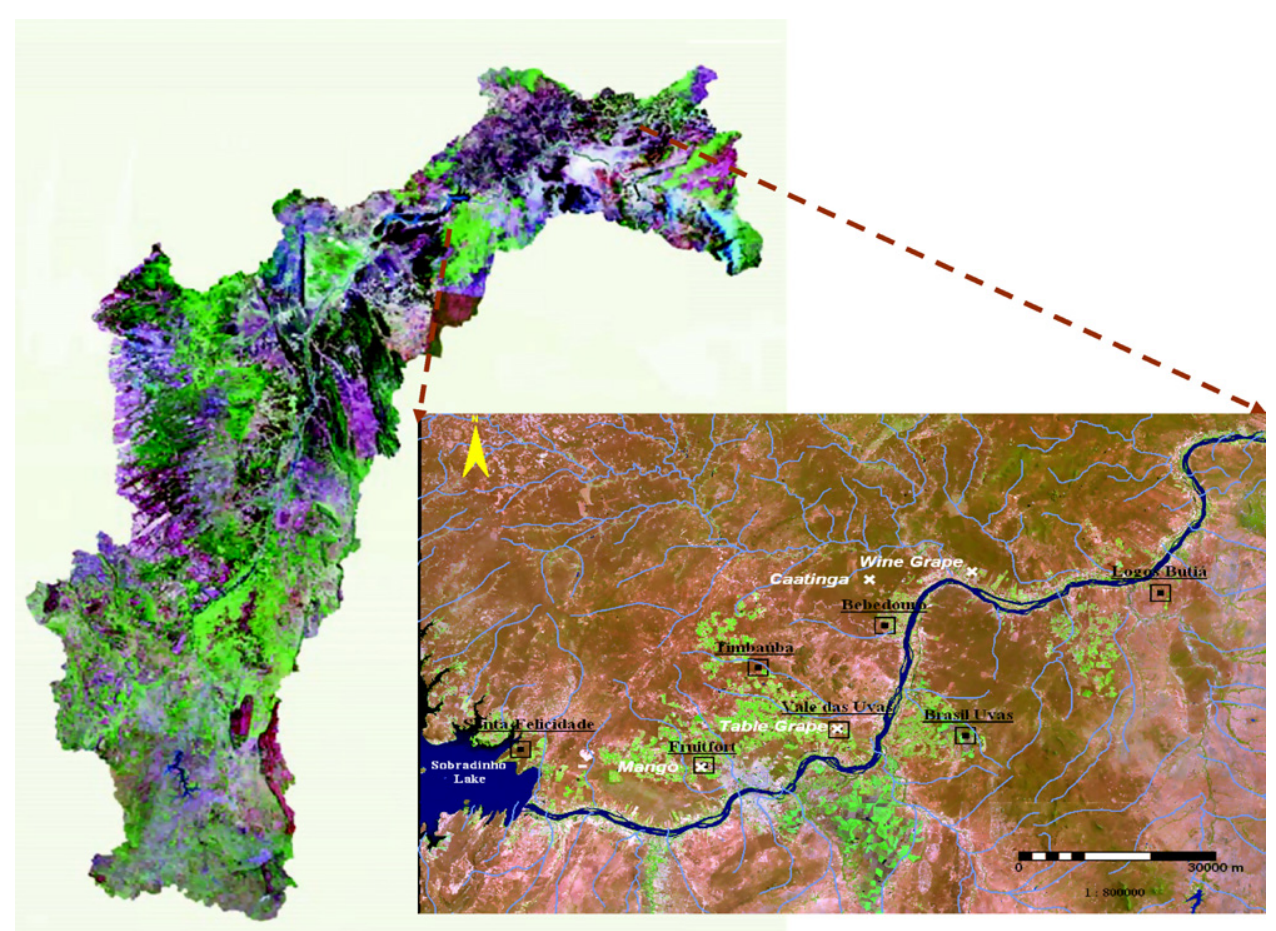

Fig. 3 - The São Francisco River Basin and the semi-arid region around the town of Petrolina investigated. The agrometeorological stations (black) and the flux towers (white) on irrigated crops (wine grape, table grape, mango orchard) and natural vegetation (caatinga) are indicated.

The resulting broadband planetary albedo and radiometric temperature from Eqs. (2) and (3) needs to be corrected atmospherically for acquiring the land surface counterparts.

\subsection{Field measurements}

The region with the field energy balance experiments and the network of agro-meteorological stations used in this study is shown in Fig. 3. The green areas in the study region represent irrigated crops while the darker ones consist of natural vegetation. The thin blue lines are drainage lines.

The coordinates and details of each plot being equipped with flux towers are shown in Table 2. The experimental setups are described in Teixeira et al. (2007, 2008a,b). The routine weather data from the seven automatic agro-meteorological stations were used for SEBAL calculations and to compute the reference evapotranspiration $\left(\mathrm{ET}_{0}\right)$ by the Penman-Monteith method (Allen et al., 1998). The stations are equipped with pyranometers, anemometers, net radiometers, sensors for air temperature and relative humidity and soil heat flux plates. Table 3 resumes the data collection in all field experiments as well in agro-meteorological stations at the vicinities of each site. Table 4 shows the averaged daily meteorological ground conditions during the overpasses days of the Landsat satellite, as well the vegetated surface types considered for each image. These days cover periods with a high (6.2 $\mathrm{mm} \mathrm{d}^{-1}$ ) and low (3.8 $\left.\mathrm{mm} \mathrm{d}^{-1}\right) \mathrm{ET}_{0}$. The average value of this last parameter for all days was $5.1 \mathrm{~mm} \mathrm{~d}^{-1}$.

\section{Calibration of the empirical relationships}

\subsection{Satellite-measured variables}

\subsubsection{Surface albedo, $\alpha_{0}$}

The atmosphere disturbs the signal reaching the satellite sensor. The satellite registered radiances are, therefore, affected by the atmospheric interaction in the radiative transfer path. Part of $R_{G}$ is scattered back to the satellite before it reaches the earth surface. A correction is deemed necessary to estimate surface albedo $\left(\alpha_{0}\right)$. Following Menenti et al. (1989), a simplified linear relationship of the following

Table 2 - Field energy balance experiments used to calibrate and validate SEBAL in Low-Middle São Francisco River basin.

\begin{tabular}{lcccc} 
Vegetation & Location (latitude, longitude) & Area (ha) & Irrigation system & Method of measurements \\
\hline Wine grape (WG) & $9^{\circ} 16^{\prime} 01.73^{\prime \prime} \mathrm{S} ; 40^{\circ} 11^{\prime} 32.62^{\prime \prime} \mathrm{W}$ & 4.13 & Drip & Bowen ratio \\
Table grape (TG) & $9^{\circ} 18^{\prime} 40.84^{\prime \prime} \mathrm{S} ; 40^{\circ} 22^{\prime} 29.47^{\prime \prime} \mathrm{W}$ & 5.13 & Micro sprinkler & Bowen ratio \\
Mango (MG) & $9^{\circ} 22^{\prime} 32.20^{\prime \prime} \mathrm{S} ; 40^{\circ} 33^{\prime} 54.23^{\prime \prime} \mathrm{W}$ & 11.92 & Micro sprinkler & Eddy covariance \\
Caatinga (CT) & $9^{\circ} 03^{\prime} 30.71^{\prime \prime} \mathrm{S} ; 40^{\circ} 19^{\prime} 45.21^{\prime \prime} \mathrm{W}$ & N/A & Not irrigated & Eddy covariance
\end{tabular}


Table 3 - The field data over the period July 2001 to January 2007 in the four energy balance field experiments and agrometeorological stations.

Site

Wine grape

Table grape

Mango orchard

Caatinga

Agro-meteorological stations
Instrumentation

- Tower-Bowen ratio system: gradients of air temperature and humidity.

- Radiation: short wave radiation (downward and upward) and net of all wave radiation above the canopy.

- Microclimatic conditions: air temperature and relative humidity at canopy level and gradient of wind speed above the canopy.

- Soil heat flux at a depth of $2 \mathrm{~cm}$.

- Soil moisture at the depths of: 20,40 and $60 \mathrm{~cm}$

- Tower-Bowen ratio system: gradients of air temperature and humidity.

- Radiation: short wave radiation (downward) and net of all wave radiation above and under the canopy.

- Microclimatic conditions: wind speed above the canopy (one level), air temperature and relative humidity at canopy level.

- Soil heat flux at a depth of $2 \mathrm{~cm}$.

- Soil moisture at the depths of: 20,40 and $60 \mathrm{~cm}$

- Tower-Bowen ratio and eddy correlation systems: gradients of air temperature and humidity; fluctuations of wind speed, air temperature and absolute humidity; and frictional velocity.

- Radiation: short wave radiation (downward and upward) and net of all wave radiation.

- Microclimatic conditions: wind speed above the canopy (one level), air temperature and humidity at canopy level.

- Soil heat flux at a depth of $2 \mathrm{~cm}$.

- Soil moisture at the depths of: $20,40,60,80,100,120 \mathrm{~cm}$.

- Tower-Eddy correlation system: fluctuations of wind speed, air temperature and absolute humidity; and frictional velocity.

- Radiation: short wave radiation (downward and upward), long wave radiation (downward and upward) and net of all wave radiation.

- Microclimatic conditions: wind speed above the vegetation (one level), air temperature and humidity at leaves level.

- Soil heat flux at a depth of $2 \mathrm{~cm}$.

- Air pressure

- Rainfall above the vegetation

Wind speed and direction, air temperature and relative humidity, incident short wave radiation, net of all wave radiation and soil heat flux at a depth of $2 \mathrm{~cm}$ bellow grass. type has been sought for correcting all atmospheric disturbances:

$\alpha_{0}=a \alpha_{\mathrm{p}}+b$
Combination of field measurements of $\alpha_{0}$ with Landsat calculations of $\alpha_{\mathrm{p}}$ resulted in physical meaningful results: $a=0.61$ and $b=0.08$. The coefficient $a$ is the two-way transmittance through the atmosphere, leading to an average

Table 4 - Daily values of weather variables on Landsat overpass days. The averaged data of seven agro-meteorological stations and land surface types used for SEBAL calibration and validation are presented: extra-terrestrial solar radiation

$\left(R_{a}\right)$; global solar radiation $\left(R_{G}\right)$, air temperature $(T)$, relative humidity $(R H)$, vapour pressure deficit $(D)$, wind speed at 3 m above the ground $(u)$ and reference evapotranspiration $\left(E T_{0}\right)$. All values represent $24 \mathrm{~h}$ periods.

\begin{tabular}{|c|c|c|c|c|c|c|c|c|}
\hline Day/year & Surface type & $R_{a}\left(M^{\prime} m^{-2} d^{-1}\right)$ & $\mathrm{R}_{\mathrm{G}}\left(\mathrm{MJ} \mathrm{m}^{-2} \mathrm{~d}^{-1}\right)$ & $\mathrm{T}\left({ }^{\circ} \mathrm{C}\right)$ & $\mathrm{RH}(\%)$ & $\mathrm{D}(\mathrm{kPa})$ & $u\left(\mathrm{~m} \mathrm{~s}^{-1}\right)$ & $\mathrm{ET}_{0}\left(\mathrm{~mm} \mathrm{~d}^{-1}\right)$ \\
\hline $253 / 2001$ & WG & 35.7 & 25.0 & 27.4 & 52 & 1.8 & 3.0 & 4.4 \\
\hline 2772001 & WG & 37.1 & 24.5 & 29.2 & 46 & 2.2 & 3.2 & 4.5 \\
\hline $187 / 2003$ & TG, CT & 28.7 & 21.5 & 23.5 & 54 & 1.3 & 1.9 & 3.8 \\
\hline $267 / 2003$ & TG, CT & 38.3 & 22.2 & 25.8 & 48 & 1.7 & 2.4 & 5.0 \\
\hline $286 / 2004$ & MG, CT & 37.1 & 26.7 & 28.1 & 46 & 2.1 & 3.4 & 6.0 \\
\hline $318 / 2004$ & MG, CT & 39.4 & 28.0 & 31.4 & 39 & 2.8 & 2.5 & 6.2 \\
\hline $288 / 2005$ & MG, CT & 37.0 & 27.4 & 28.1 & 45 & 2.1 & 3.0 & 5.8 \\
\hline $320 / 2005$ & MG, CT & 39.4 & 28.0 & 28.2 & 48 & 2.0 & 2.6 & 6.0 \\
\hline $211 / 2006$ & MG, CT & 31.1 & 21.8 & 27.0 & 53 & 1.7 & 2.0 & 4.0 \\
\hline $022 / 2007$ & MG, CT & 40.7 & 27.7 & 29.6 & 46 & 2.3 & 1.4 & 5.2 \\
\hline Mean & - & 36.5 & 25.3 & 27.4 & 52 & 1.8 & 3.0 & 5.1 \\
\hline
\end{tabular}

Irrigated crops: Wine grape (WG), table grape (TG) and mango orchard (MG).

Natural vegetation: Caatinga (CT). 

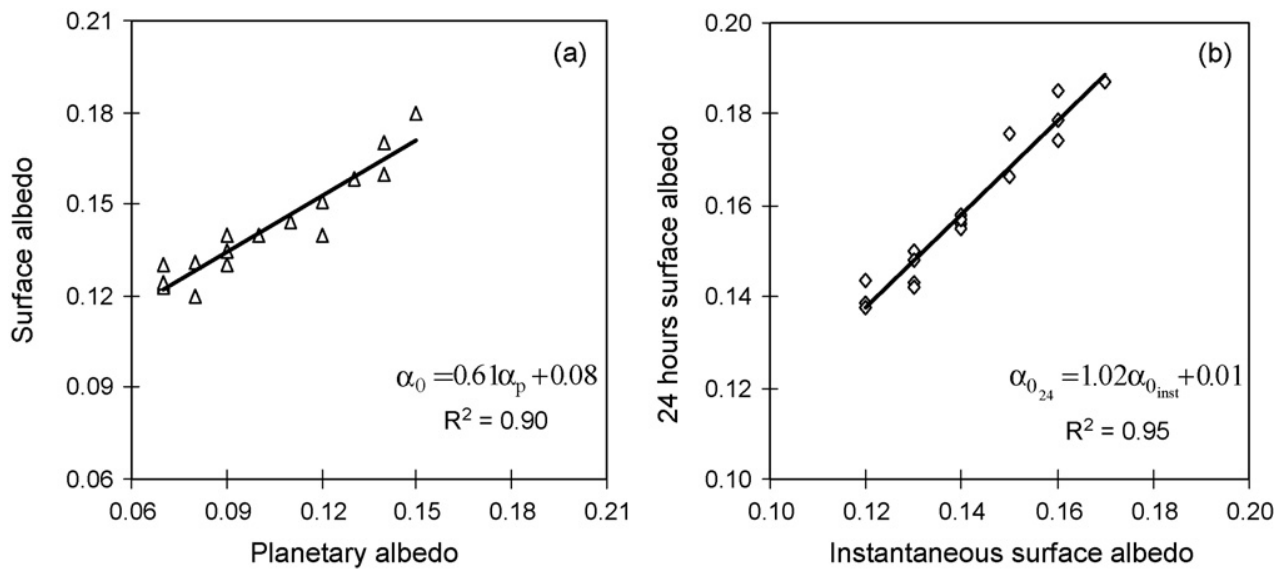

Fig. 4 - Relationship between surface albedo from the field energy balance experiments and their counterparts from satellite overpass measurements: (a) instantaneous values of $\alpha_{0}$ and $\alpha_{\mathrm{p}}$; (b) daily (subscript 24) and instantaneous (subscript inst) values of $\alpha_{0}$.

single pathway atmospheric transmissivity of $a^{0.5}=0.78$. The latter is a value for clear sky radiation (e.g. Allen et al., 1998). The instantaneous regression analysis is shown in Fig. 4a.

Eq. (4) was applied to all Landsat images for determining the spatial variation of $\alpha_{0}$. The Landsat overpass measurements yielded instantaneous values of surface albedo that were systematically lower than those for $24 \mathrm{~h}$. Hence, a second regression equation was necessary to retrieve the daily from instantaneous values (Fig. 4b). The relationship depicted in Fig. $4 \mathrm{~b}$ has been considered in the computations of the 24- $\mathrm{h}$ values of net radiation required for the determination of daily energy partition and ET.

\subsubsection{Surface temperature, $T_{0}$}

The standard equations for heat transfer require aerodynamic surface temperature. The determination of the components of the surface radiation and energy balances according to the parameterizations outlined required the vertical temperature difference $(\Delta T)$ between two heights, which was derived from the radiation temperature measured by the field data sets, $H$, air temperature above the canopies, and the aerodynamic resistance- $r$ a (Smith et al., 1989).

$\Delta \mathrm{T}=\frac{\mathrm{Hr} r_{\mathrm{a}}}{\rho_{\mathrm{a}} c_{p}}$

where $\rho_{\mathrm{a}}$ and $c_{p}$ are the air density and air specific heat at constant pressure, respectively. Field values of $r_{a}$ were determined by flux profile in vineyards (Teixeira et al., 2007) and by eddy covariance measurements in mango orchard and caatinga (Teixeira et al., 2008a,b).

International experiments have demonstrated that, other than for a thin surface such as bare soil or a short canopy, a difference of several degrees can be observed between radiometric and aerodynamic surface temperature (Troufleau et al., 1997). The latter implies that the radiometric temperature from Landsat is an ill-provision of aerodynamic surface temperature required for solving $H$.

Cleugh and Dunin (1995) compared aerodynamic surface temperatures $\left(T_{0}\right)$ with canopy radiometric temperatures and found excellent agreement for dense fully closed wheat. However, when this crop is sparse, large differences were observed; especially when LAI was lower than 2. For sparse or composite vegetation, the radiometric surface temperature was found to be much higher than $T_{0}$ from flux inversion (Kalma and Jupp, 1990).

In addition to the differences between radiometric and aerodynamic temperatures, part of the spectral thermal infrared radiation from the land surface is absorbed by the atmosphere and emitted upwards (path radiance). The thermal radiation measured by satellite sensors thus needs to be corrected for both atmosphere emission and the difference between radiometric and aerodynamic surface temperature. To correct these conjugated effects the field results from Eq. (5) were used to fit a linear relationship between $T_{0}\left(T_{0}=T+\Delta T\right)$ and $T_{\text {sat }}$ :

$\mathrm{T}_{0}=a \mathrm{~T}_{\mathrm{sat}}+b$

The coefficients for multiple Landsat days appear to be $a=1.07$ and $b=-20.17$ (Fig. 5). Eq. (6) was applied to all Landsat images to obtain the spatial variation of $T_{0}$ to be used in solving H.

It is realized that a physically based atmospheric correction would include transmittance and reflectance of spectral radiances (e.g. Schmugge et al., 1998), but for practical reasons Eqs. (4) and (6) are doable.

\subsection{Land measured variables}

3.2.1. Broadband apparent emissivity of the atmosphere, $\varepsilon_{a}$ Measured $R_{\mathrm{L} \downarrow}$ over caatinga-in combination with T-allowed us to inspect the instantaneous apparent emissivity of the atmosphere $\left(\varepsilon_{\mathrm{a}}\right)$. The SEBAL-based equation for the satellite overpass time reads as:

$\varepsilon_{\mathrm{a}}=a\left(-\ln \tau_{\mathrm{sw}}\right)^{b}$

where the regression coefficients become $a=0.942$ and $b=0.103$ as shown in Fig. 6 , and $\tau_{\mathrm{sw}}$, the atmospheric trans- 


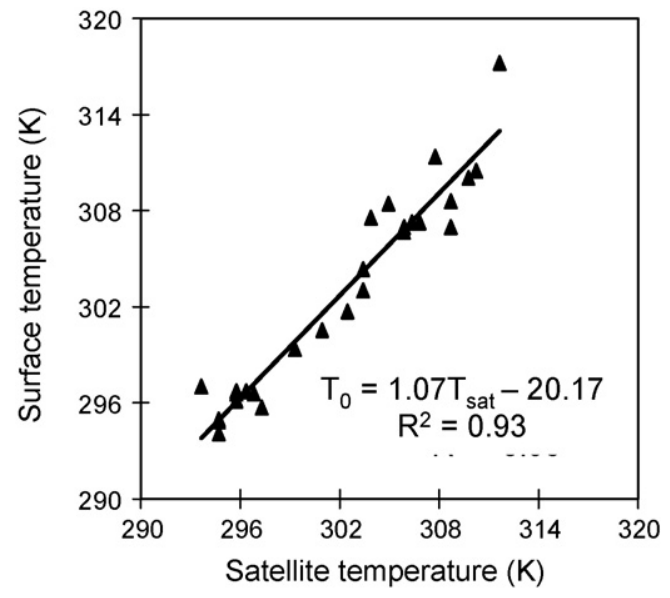

Fig. 5 - Relationship between surface temperature from the field energy balance experiments and their counterparts from satellite overpass measurements.

missivity, is the ratio of instantaneous solar radiation measured at the ground surface to that for the top of the atmosphere $\left(R_{G} / R_{a}\right)$. The subscript sw means shortwave radiation.

Note that the daily values of Eq. (7) are with $a=0.936$ and $b=0.114$ slightly different (Teixeira et al., 2008b), and also differ from those obtained for Idaho $(a=0.85 ; b=0.09$; source: Allen et al., 2000) and Egypt $(a=1.08 ; b=0.265$; source: Bastiaanssen, 1995). In fact, the instantaneous values for the Low-Middle São Francisco River basin are between those for Idaho and Egypt.

Eq. (7) was thereafter applied, together interpolated T, to all Landsat images to obtain the regional long wave emitted from the atmosphere $\left(R_{L \downarrow}\right)$ in the radiation balance (Fig. 1).

\subsubsection{Broadband surface emissivity, $\varepsilon_{0}$}

Field values of emitted long wave radiation-jointly with estimates of $\mathrm{T}_{0}$-gave us the opportunity to isolate and thus to quantify the thermal infrared emissivity $\left(\varepsilon_{0}\right)$. Following Van der Griend and Owe (1993), the results of $\varepsilon_{0}$ from radiation balance experiments were correlated with NDVI from Landsat images (Fig. 7):

$\varepsilon_{0}=a \ln \mathrm{NDVI}+b$

The values found were 0.059 and 1.004 for the coefficients $a$ and $b$, respectively. The original coefficients are $a=0.047$ and $b=1.009$, hence slightly different (Bastiaanssen, 1995). The values of $\varepsilon_{0}$ were used for the estimation of $R_{\mathrm{L} \uparrow}$ in the radiation balance (Fig. 1).

3.2.3. Surface roughness length for momentum transfer, $z_{0 m}$ Field values of roughness length for momentum transfer $\left(z_{0 m}\right)$ in natural vegetation and irrigated crops are described by Teixeira et al. (2008b). To estimate regional values of $z_{0 m}$ Allen et al. (2007a) suggested a simplified expression based on $\alpha_{0}$ and NDVI. The inclusion of these both indices helps to distinguish between vegetation having different architecture but similar values of NDVI. For example table grape can have the same

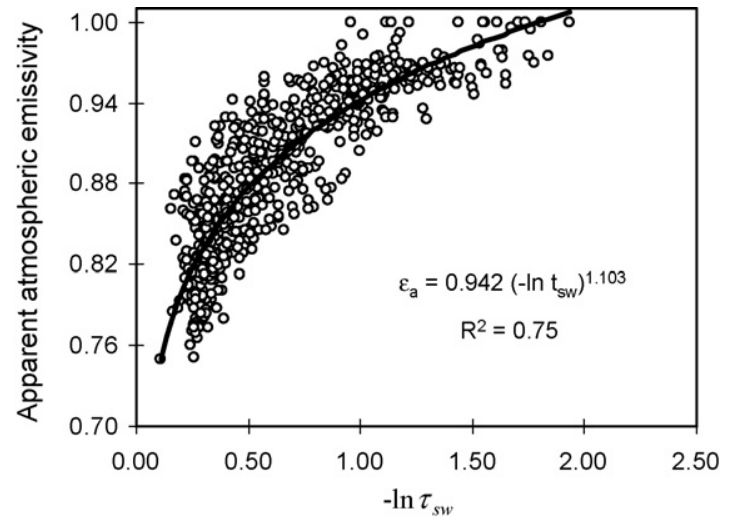

Fig. 6 - Satellite overpasses relationship between the broadband apparent atmospheric emissivity and shortwave atmospheric transmissivity.

NDVI values as mango orchard, but at a substantially lower leaf area index (LAI).

The simplified approach below was tested for the mixture of agricultural and natural ecosystems:

$\left.z_{0 m}=\exp \left[\left(a \frac{N D V I}{\alpha_{0}}\right)\right)+b\right]$

The regression coefficients were $a=0.26$ and $b=-2.21$ (Fig. 8). The coefficient of determination is rather encouraging $\left(R^{2}=0.92\right)$ for describing a difficult land surface parameter by some simplified remote sensing variables. Eq. (9) was scaled up and used in calculating regional friction velocity $\left(u_{*}\right)$ and then regional $H$.

\subsubsection{Soil heat flux, $G$}

Field measurements of $G$ and $R_{n}$ were used together with satellite measurements of surface temperature $\left(T_{0}\right)$ in ${ }^{\circ} \mathrm{C}$, surface albedo $\alpha_{0}$, and NDVI to test the following multiple regression equation:

$\frac{G}{R_{\mathrm{n}}}=\mathrm{T}_{0}\left(a \alpha_{0}+b\right)\left(1-0.98 \mathrm{NDVI}^{4}\right)$

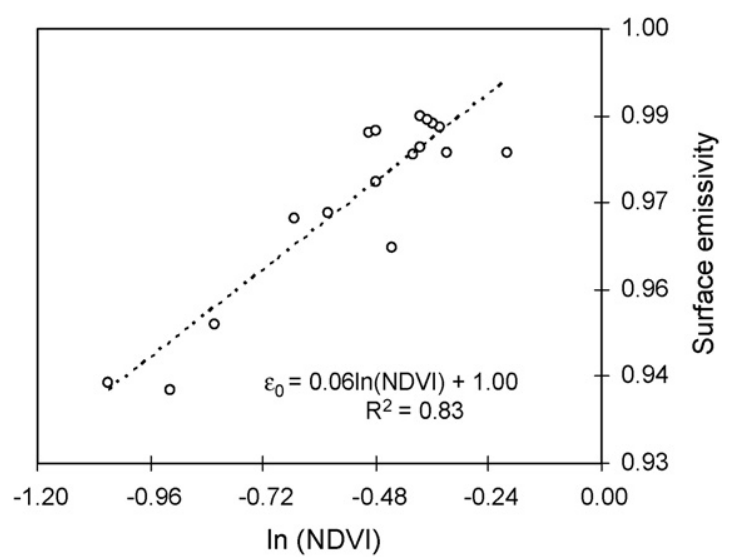

Fig. 7 - Relationship between broadband surface emissivity of vegetated surfaces and the Normalized Difference Vegetation Index (NDVI). 


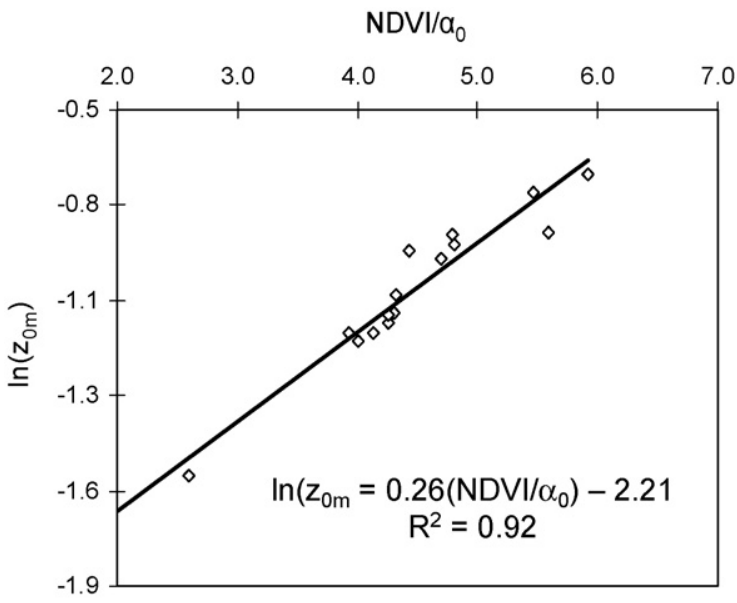

Fig. 8 - Relationship between the roughness length for momentum transport $\left(\mathrm{z}_{\mathrm{Om}}\right)$ and the ratio of the Normalized Difference Vegetation Index (NDVI) to surface albedo $\left(\alpha_{0}\right)$.

The results reveal $a=-0.11, b=0.02$ to be the best set of locally calibrated coefficients. These coefficients were obtained from the multiple regression of $G / R_{n}$ with $\alpha_{0}, T_{0}$ and NDVI (Fig. 9). The original coefficients are different with $a=0.0074$ and $b=0.0038$ for the condition where they were found (Bastiaanssen, 1995). The differences can be explained by the conditions of daily irrigation and bigger LAI of irrigated fruit crops in the Low-Middle São Francisco River basin, Brazil. $G$ is a difficult term to evaluate and care should be used in its computation by Eq. (10). The values should be checked against actual measurements on the ground for specific conditions.

\subsubsection{Sensible heat flux, $H$}

The computation of $\mathrm{H}$ by SEBAL algorithm requires two "anchor" pixels, also referred to as the hot and the cold pixels. In this study, the hot and cold pixels were represented by the natural vegetation (caatinga) and irrigated crop (mango orchard), respectively. To compute $H$ from Eq. (5), the near

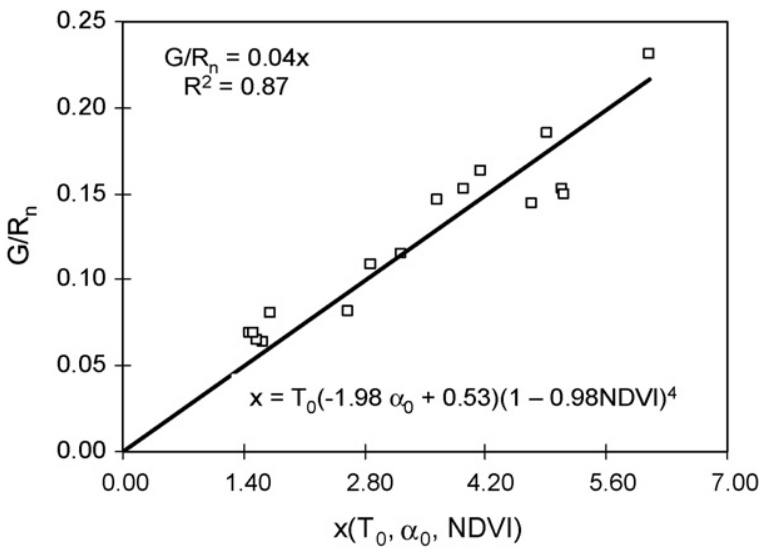

Fig. 9 - Relationship between the ratio of soil heat flux (G) over net radiation $\left(R_{n}\right)$ with surface temperature $\left(T_{0}\right)$, surface albedo $\left(\alpha_{0}\right)$ and the Normalized Difference Vegetation Index (NDVI).

surface temperature difference $(\Delta T)$ for each pixel is given as $\left(T_{1}-T_{2}\right)$, the temperature difference between two heights $\left(z_{1}\right.$ and $z_{2}$ ). The regionalization of $\Delta T$ occurs by assuming a linear relationship with $\mathrm{T}_{0}$ :

$\Delta \mathrm{T}=a \mathrm{~T}_{0}+b$

where $a$ and $b$ are the fitting coefficients.

The generalized annual curves of $\mathrm{ET}_{\mathrm{ET}}$ for the time of satellite overpass (9:30) of these two contrasting vegetation types have been used to estimate $H$ (and thus $\Delta T$ ) at these specific locations (Fig. 10). There were two complete years of flux data in mango orchard and caatinga, however, data of 2005 were used because during the year of 2004 unusual storms occurred. These ET/ET $\mathrm{E}_{0}$ curves were used for other years together the values of $\mathrm{ET}_{0}$ for the satellite overpass days.

Fig. 10 shows that the $\lambda E$ of natural vegetation, caatingafor instance-is not negligible, but has an ET/ET 0 value around 0.20 during the dry season and even more than 0.90 during the wet season.

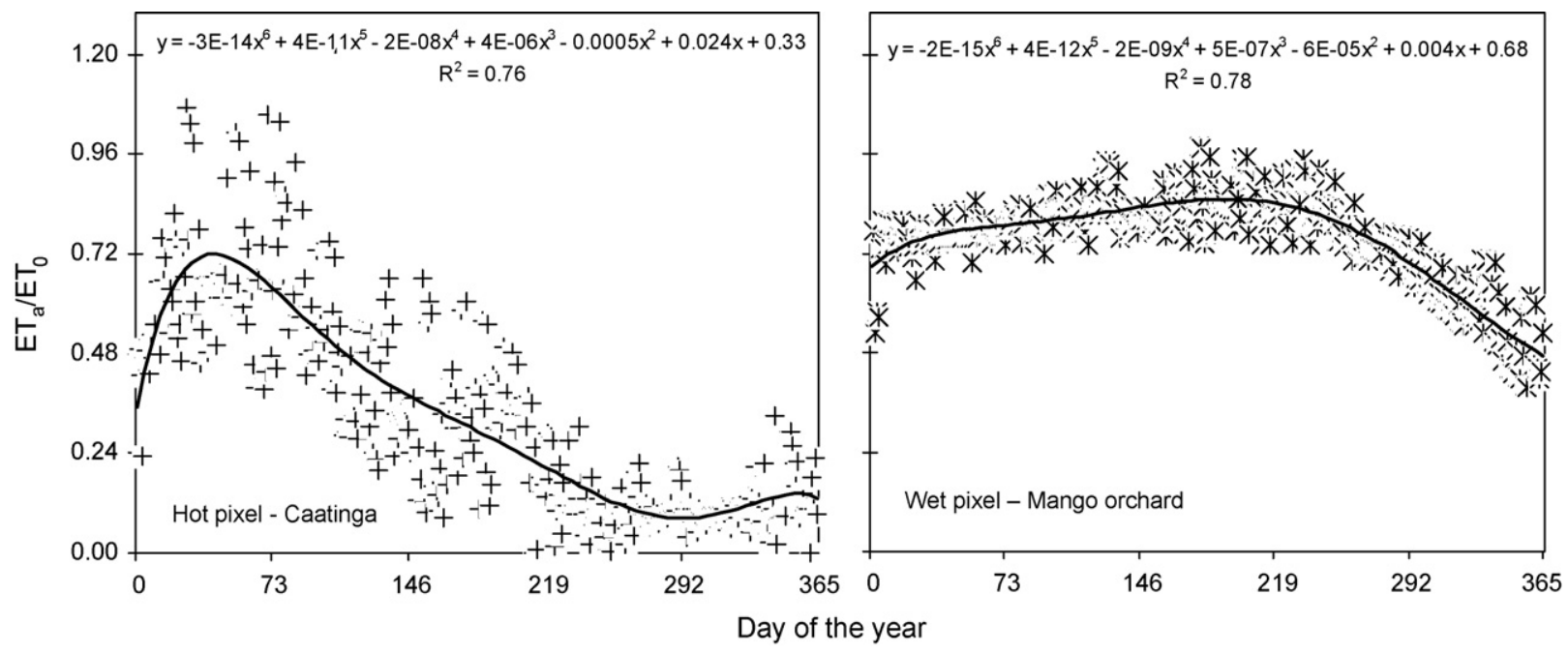

Fig. 10 - Curves of (ET/ET $)$ for the cold (mango orchard) and hot (caatinga) pixels. Data for 2005 were taken. 
The advantage of using known land use together with ET/ $\mathrm{ET}_{\mathrm{O}}$ values is that the assumptions of zero sensible or latent heat fluxes are not strictly required as originally (Bastiaanssen, 1995), which makes it possible to calculate regional ET also during the rainy period.

In the cold pixel (irrigated mango orchard) the value of $H_{\text {cold }}$ could be approximated as:

$H_{\text {cold }}=R_{n_{-} \text {cold }}-G_{\text {cold }}-\left(\frac{E T}{E T_{0}}\right)_{\text {cold }} \mathrm{ET}_{0}$

where $\left(E T / E T_{0}\right)_{\text {cold }}$ is the ratio valid for the mango orchard according to the time of the year (Fig. 10), $R_{\mathrm{n} \_ \text {cold }}$ is the net radiation, $G_{\text {cold }}$ is the soil heat flux and $\mathrm{ET}_{0}$ is the reference evapotranspiration at satellite overpass for the place where the flux tower was in the irrigated mango orchard. The energy balance terms were taken from satellite results, while for $\mathrm{ET}_{0}$ the weather values at the agro-meteorological stations were interpolated by using the seven agro-meteorological stations.

At the hot pixel, the values of $H_{\text {hot }}$ were calculated in the same way using values of $\left(\mathrm{ET}_{\mathrm{a}} / \mathrm{ET}_{0}\right)_{\text {hot }}$ valid for caatinga according to the time of the year (Fig. 10); and net radiation $\left(R_{n_{-} h o t}\right)$, soil heat flux ( $\left.G_{\text {hot }}\right)$ and reference evapotranspiration $\left(\mathrm{ET}_{0}\right)$ for the place where the flux tower was in the natural vegetation:

$H_{\text {hot }}=R_{\text {n_hot }}-G_{\text {hot }}-\left(\frac{E T}{E T_{0}}\right)_{\text {hot }} E T_{0}$

The values of $H_{\text {cold }}$ and $H_{\text {hot }}$ were used to infer $\Delta$ T applying Eq. (5) in an iterative process starting with neutral conditions till stabilization of $\Delta \mathrm{T}$ at the cold and the hot pixels after successive atmospheric stability corrections for $r_{a}$. The calculations of the regression coefficients of $\Delta T$ versus $T_{0}$ (Eq. (11)) were done in the spreadsheet and were variable for each Landsat image acquisition day. The $a$ and $b$ values based on degrees Kelvin varied from 0.54 to 1.16 and from -160.8 to -348.2 , respectively, found for the images of January (lowest $a$ and highest $b$ ) and November (highest $a$ and lowest $b$ ), representing the wettest and the warmest months of the year, respectively (Fig. 11). Eq. (11) and the image date specific regression coefficients were applied to all Landsat images for acquirement of $H$. The values of $T$ were interpolated from the 7 agro-meteorological stations.

The values of $H$ for each pixel were calculated using Eq. (5) first assuming neutral conditions. The drag force between land and atmosphere is accounted for $r_{\mathrm{a}}$, and this parameter required the surface roughness conditions $z_{0 h}$ and friction velocities $u_{*}$ to be specified:

$r_{\mathrm{a}}=\frac{\ln (\mathrm{z}-\mathrm{d}) / \mathrm{z}_{0 \mathrm{~h}}-\psi_{\mathrm{h}}((\mathrm{z}-\mathrm{d}) / \mathrm{L})}{k u_{*}}$

where $z_{0 h}(m)$ is the roughness length governing transfer of heat and vapour away from the land surface into the atmosphere, $k$ is the von Karman's constant (0.41), $z(m)$ is the reference height taken as $5 \mathrm{~m}, d(\mathrm{~m})$ is the displacement height taken as $4.67 \mathrm{z}_{0 \mathrm{~m}}, \psi_{\mathrm{h}}$ is the stability correction due to buoyancy and $L$ is Obukhov length.

The atmospheric surface-layer similarity theory was applied, using universal functions suggested by Businger et al. (1971) for solving the integrated stability functions of temperature $\left(\Psi_{\mathrm{h}}\right)$ and momentum $\left(\Psi_{\mathrm{m}}\right)$. The following expressions were used for unstable situations:

$\mathrm{Y}_{\mathrm{h}}\left(\frac{z-d}{\mathrm{~L}}\right)=2 \ln \left(\frac{1+x^{2}}{2}\right), \quad$ with $x=\left(1-16 \frac{z-d}{L}\right)^{1 / 4}$

$\Psi_{\mathrm{m}}\left(\frac{z-d}{L}\right)=2 \ln \left(\frac{1+x}{2}\right)+\ln \left(\frac{1+x^{2}}{2}\right)-2 \arctan (x)+\frac{\pi}{2}$

where $\mathrm{x}$ is an empirical parameter, $\mathrm{z}$ for $\Psi_{\mathrm{h}}$ was considered $5 \mathrm{~m}$ and for $\Psi_{\mathrm{m}}$ it was considered $200 \mathrm{~m}$. L was calculated as:

$L=-\frac{\rho_{\mathrm{a}} c_{p} u_{*}^{3} \mathrm{~T}}{k g H}$

where $\rho_{\mathrm{a}}$ is the air density $\left(\mathrm{kg} \mathrm{m}^{3}\right), c_{p}$ is the air specific heat $\left(1004 \mathrm{~J} \mathrm{~kg}^{-1} \mathrm{~K}^{-1}\right)$, $\mathrm{T}$ is the air temperature $(\mathrm{K}), \mathrm{g}$ is the gravitational constant $\left(9.81 \mathrm{~m} \mathrm{~s}^{-2}\right)$, and $\mathrm{H}$ is the sensible heat flux $\left(\mathrm{W} \mathrm{m}^{-2}\right)$.

The friction velocity $\left(u^{*}\right.$ expressed in $\mathrm{m} \mathrm{s}^{-1}$ ) by:

$u_{*}=\frac{u k}{\ln \left(z-d / z_{0 m}\right)-\Psi_{m}}$

where $u$ is the wind speed at $200 \mathrm{~m}\left(\mathrm{~m} \mathrm{~s}^{-1}\right), k$ is von Karman's constant (0.41), $z_{0 m}$ is the roughness length for each pixel $(\mathrm{m}), k$ is von Karman's constant (0.41), and $\Psi_{\mathrm{m}}$ is the stability correction for momentum transport at the height $\mathrm{z}=200 \mathrm{~m}$.

The regional values for roughness length for moment transfer was obtained from Eq. (9) and corrected value for $r_{a}$ was computed during each iteration using Eq. (14) for $z=5 \mathrm{~m}$. Next, the final corrected value for $H$ was obtained at each pixel (see Fig. 2), which was used in the computation of the regional instantaneous latent heat flux.

\subsubsection{Evaporative fraction, $E F$}

According to our field data for mango orchard and natural vegetation, the instantaneous evaporative fraction at daylight time was lower than for the $24 \mathrm{~h}$ periods, while vineyards results showed no big differences between these time scales (Teixeira et al., 2008b). A straightforward regression equation was then applied to scale the instantaneous ET to daily values according to:

$\mathrm{ET}_{24}=a \mathrm{EF}_{\text {isnt }} \mathrm{R}_{\mathrm{n} \_24}$

where $\mathrm{ET}_{24}$ and $\mathrm{R}_{\mathrm{n} \_24}$ are the actual evapotranspiration and the net radiation for $24 \mathrm{~h}\left(\mathrm{~mm} \mathrm{~d}^{-1}\right)$ and $a$ is a correction coefficient, which was found to be 1.18 for the Brazilian semi-arid conditions. Note that the $\mathrm{EF}_{\text {inst }}$ represents the instantaneous value at satellite overpass.

The net radiation for $24 \mathrm{~h}$ was calculated with albedo values $\left(\alpha_{0 \_24}\right)$, global solar radiation $\left(R_{\mathrm{G}_{2} 24}\right)$ and atmospheric transmissivity $\left(\tau_{\mathrm{SW} \_24}\right)$ for this time scale, applying the Slob equation (Bruin de, 1987; Bruin de and Stricker, 2000):

$R_{\mathrm{n} \_24}=\left(1-\alpha_{0 \_24}\right) R_{\mathrm{G} \_24}-a \tau_{\mathrm{SW} \_24}$

The coefficient a averaged 143 for our semi-arid conditions with $R^{2}=0.80$. This value is higher than the originally 
suggested value of 110 found for the Netherlands. The difference can be ascribed to different thermal conditions between the macroclimates. As it varied as a function of $\mathrm{T}$ a regression equation between $a$ and $T$ was applied to scale $R_{n \_24}$ (Teixeira et al., 2008b).

\subsection{Photosynthetically active radiation, PAR}

The photosynthetically active radiation (PAR) is of paramount importance for the computation of biomass production. PAR $(0.4-0.7 \mu \mathrm{m})$ is a fraction of $R_{G}(0.3-3 \mu \mathrm{m})$ that can be

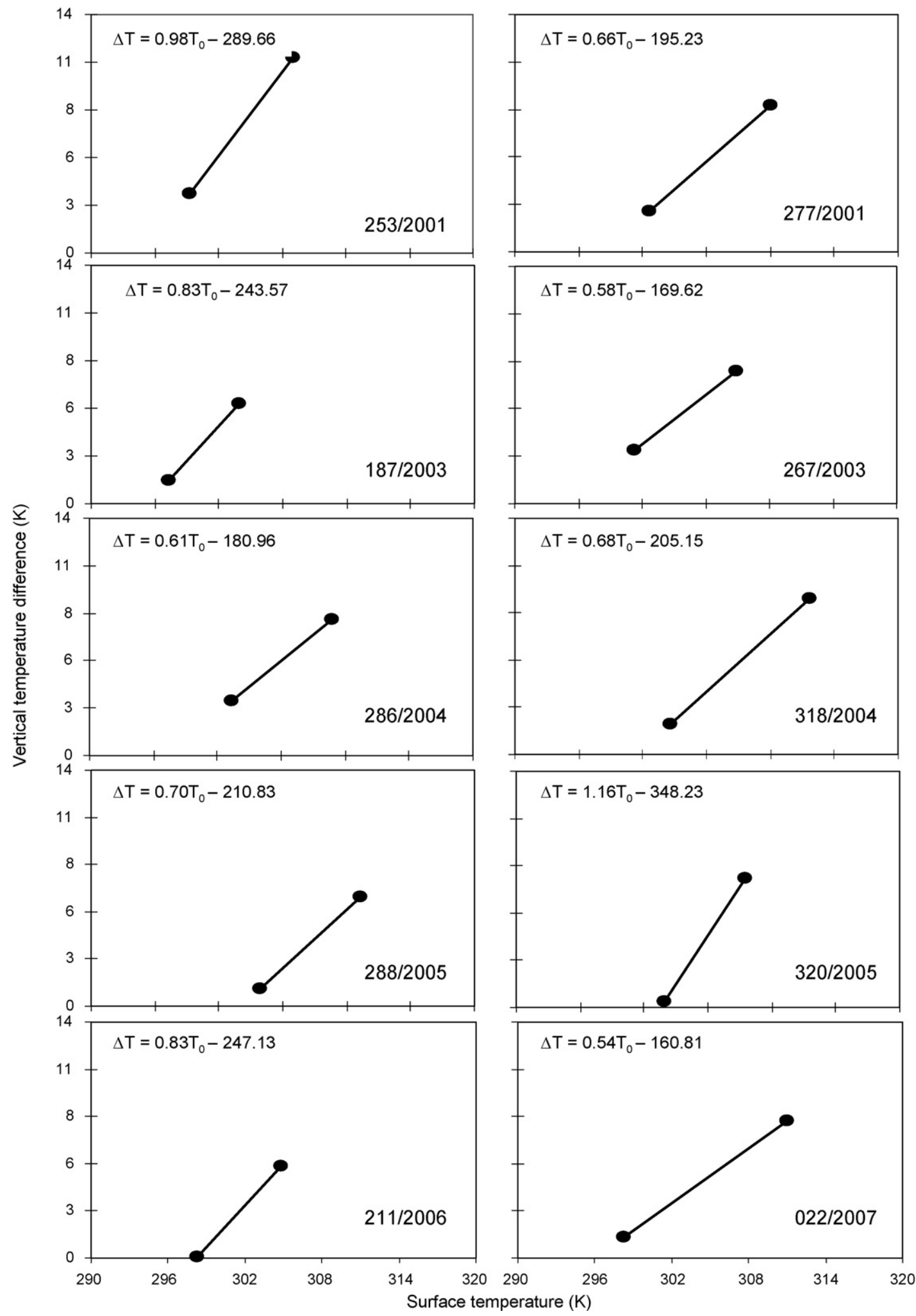

Fig. 11 - Relationship between the vertical temperature difference and the surface temperature in the cold and hot pixels for Day/year 253/2001, 277/2001, 187/2003, 267/2003, 286/2004, 318/2004, 288/2005, 320/2005, 211/2006 and $022 / 2007$. 


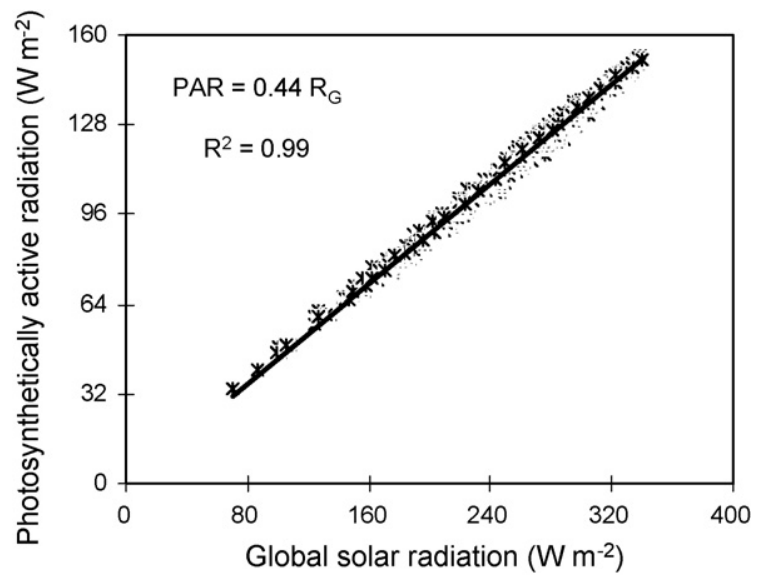

Fig. 12 - $24 \mathrm{~h}$ Relationship between photosythetically active radiation (PAR) and global solar radiation $\left(R_{\mathrm{G}}\right)$.

potentially absorbed by chlorophyll for photosynthesis in the plants. Measurements of $R_{G}$ and PAR (Kipp \& Zonen, Delft, the Netherlands) above natural vegetation allowed the parameterizations between these two solar variables (Fig. 12). The coefficient a was found to be 0.44 , being slightly lower than normally reported values ( 0.45 to 0.50$)$. The variability of the $\mathrm{PAR} / \mathrm{R}_{\mathrm{G}}$ fraction is usually ascribed to visibility, optical depth
Table 5 - Summary of the instantaneous regression

analysis for satellite and land surface variables: surface albedo- $\alpha_{0}$; planetary albedo- $\alpha_{\mathrm{p}}$; surface temperature$\mathrm{T}_{0}$; brightness temperature $-\mathrm{T}_{\text {sat; }}$ atmospheric emissivity $-\varepsilon_{\mathrm{a}}$, shortwave atmospheric emissivity $-\tau_{\text {sw; }}$; surface emissivity $-\varepsilon_{0}$, roughness length for momentum transfer $-Z_{0 m}$, soil heat flux $-G$; net radiation $-R_{n}$; photosynthetically active radiation-PAR.

\begin{tabular}{llccc} 
Variable & \multicolumn{1}{c}{ Equation } & $a$ & $b$ & $R^{2}$ \\
\hline$\alpha_{0}$ & $\alpha_{0}=a \alpha_{\mathrm{p}}+b$ & 0.61 & \multicolumn{1}{c}{0.08} & 0.90 \\
$\mathrm{~T}_{0}$ & $\mathrm{~T}_{0}=a \mathrm{~T}_{\mathrm{sat}}+b$ & 1.02 & -20.2 & 0.93 \\
$\varepsilon_{\mathrm{a}}$ & $\varepsilon_{\mathrm{a}}=a\left(-\ln \tau_{\mathrm{sw}}\right)^{b}$ & 0.94 & 0.10 & 0.75 \\
$\varepsilon_{0}$ & $\varepsilon_{0}=a \ln \mathrm{NDVI}+b$ & 0.05 & 1.01 & 0.83 \\
$\mathrm{z}_{\mathrm{Om}}$ & $\mathrm{z}_{\mathrm{mm}}=\exp \left[\left(a \frac{\mathrm{NDVI}}{\alpha_{0}}\right)+b\right]$ & 0.26 & -2.21 & 0.92 \\
$\frac{G}{\mathrm{R}_{\mathrm{n}}}$ & $\frac{G}{\mathrm{R}_{\mathrm{n}}}=\mathrm{T}_{0}\left(a \alpha_{0}+b\right)\left(1-0.98 \mathrm{NDVI}^{4}\right)$ & -0.11 & 0.02 & 0.87 \\
PAR & $\mathrm{PAR}=a R_{\mathrm{G}}$ & 0.44 & - & 0.99 \\
\hline
\end{tabular}

and ozone amount, among others (e.g. Froin and Pinker, 1995; Moran et al., 1995).

$\mathrm{PAR}=a R_{\mathrm{G}}$

A value of $a=0.44$ is then recommended in the semi-arid region of Sao Francisco River basin.

A summary for all instantaneous regression analysis is given in Table 5. All relationships presented high values of coefficient of determination, being the lowest for apparent atmospheric emissivity.
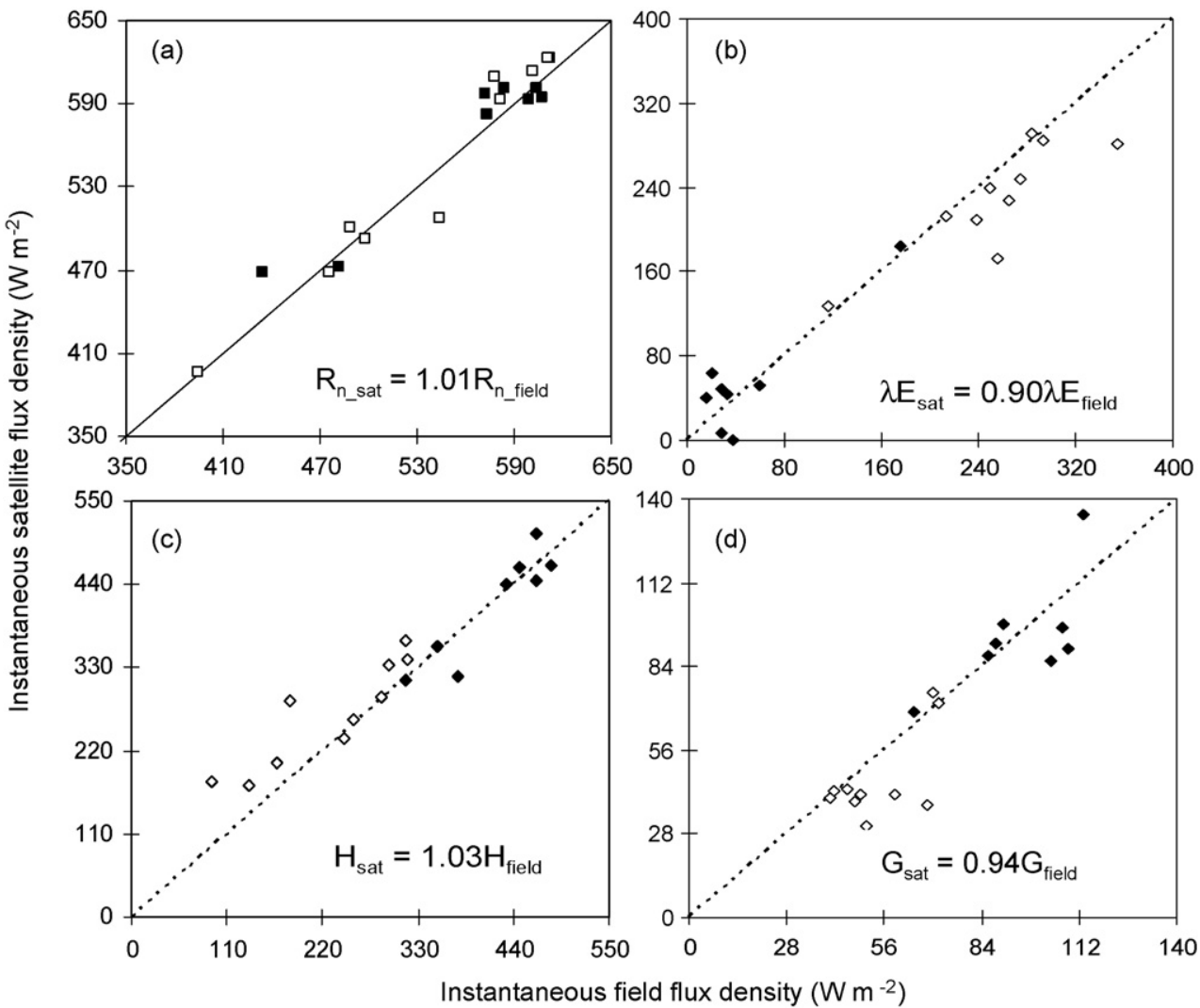

Fig. 13 - Relationship between instantaneous energy balance components obtained from SEBAL (sat) and from field energy balance measurements (field): (a) $R_{n}$-net radiation; (b) $\lambda E$-latent heat flux; (c) H-sensible heat flux; and (d) G-soil heat flux. The black and white symbols represent natural vegetation and irrigated crops, respectively. 


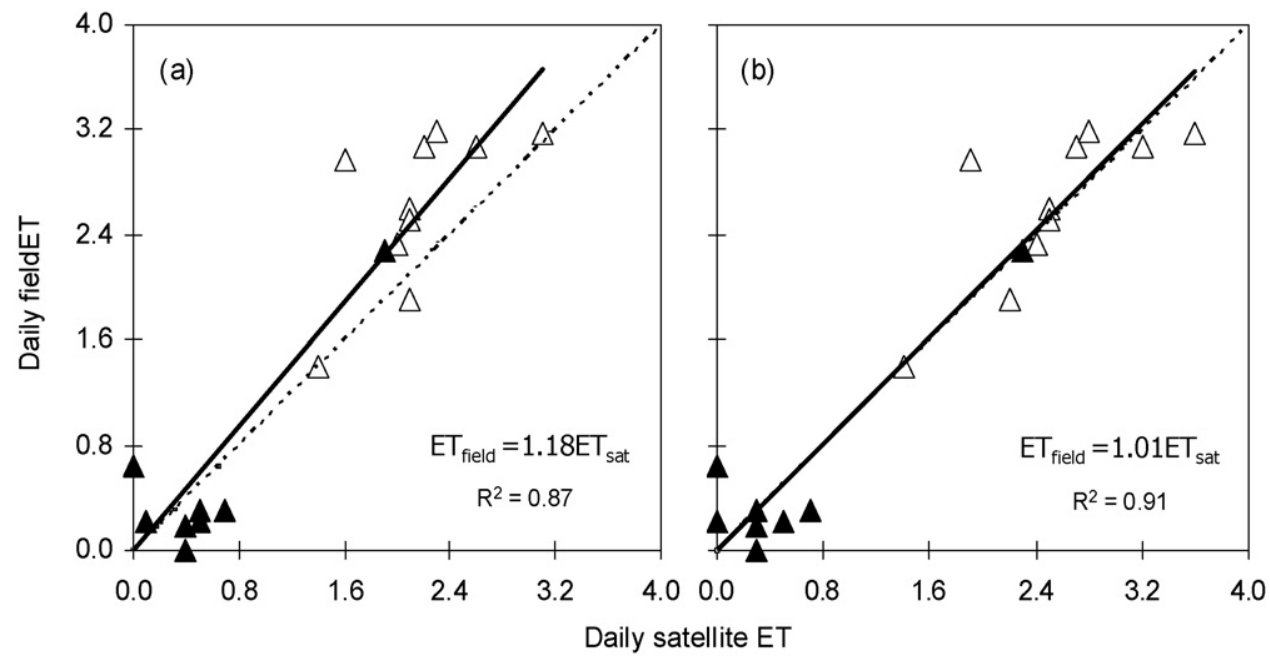

Fig. 14 - Relationships of daily actual evapotranspiration obtained from SEBAL and field measurements (ET sat $_{\text {and }}$ ET $_{\text {field }}$ ): (a) considering EF similar for instantaneous and daily scales and (b) applying the correction factor for EF. The black and white symbols are for natural vegetation and irrigated crops, respectively.

\section{Validation of the energy balance components and actual evapotranspiration}

The SEBAL procedure has been applied to all 10 different Landsat images using the calibrated empirical relationships based on field measurements. The satellite energy balance results-and notably the fluxes-were validated with field measurements. Fig. 13 shows scatter plots for instantaneous satellite and field measurements for $R_{n}$; for $\lambda E$; for $H$; and for $G$ involving all vegetation types studied.

The results showed excellent agreements on $R_{n}$ and $\lambda E$. The coefficient of determination for $R_{n}$ was $R^{2}=0.94$, with a root mean square error (RMSE) of $17.5 \mathrm{~W} \mathrm{~m}^{-2}$ and an average deviation of $1 \%$. The results for $\lambda E$ were $R^{2}=0.93$, average deviation of $10 \%$ and a RMSE of $33.8 \mathrm{~W} \mathrm{~m}^{-2}$. The differences occur typically for the higher values of $\lambda E$. The latter is a result of the bias that is observed at the lower end $H$-values. Good agreements are achieved for $\mathrm{H}$ and $\mathrm{G}$. For $\mathrm{H}$, the $\mathrm{R}^{2}$ was of 0.83 . Part of the deviations could be attributed to the estimations of $\mathrm{z}_{\mathrm{Om}}$. The RMSE was of $41.8 \mathrm{~W} \mathrm{~m}^{-2}$, with an average deviation $3 \%$. Deviations are higher in the lower end of $H$ values-thus centred on the irrigated pixels. For $G$, the local calibration yielded a $R^{2}$ of 0.81 , with the RMSE of $13.3 \mathrm{~W} \mathrm{~m}^{-2}$ and an average deviation $6 \%$ occurring typically at the lower end of $G$ values.

As instantaneous values of actual evapotranspiration are not interesting for water managers, the daily $24 \mathrm{~h}$ values were computed as well (Fig. 14a). The coefficient of 1.18 of the regression equation was applied in Eq. (19) (Fig. 14b). After the application of this regression coefficient, the relation between the SEBAL and field measurements of daily ET presented then a $R^{2}$ of 0.91 and a RMSE of $0.38 \mathrm{~mm} \mathrm{~d}^{-1}$ with a very small deviation of $1 \%\left(\mathrm{ET}_{\text {sat }}=1.01 \mathrm{ET}_{\text {field }}\right)$.

According to Bastiaanssen et al. (2008), the SEBAL model has been validated in grapes, peaches and almonds from Spain, Turkey and California. These validations revealed that accumulated values of ET predicted by the model are within several percent from the measured values. Considering that the field measurements have their own sources of errors, the accuracy of the actual study is considered satisfactory.

The results of regional ET and PAR were then scaled up and used for regional actual evapotranspiration, biomass production and crop water productivity analyses in semi-arid region of São Francisco River basin and discussed in the accompanying paper (Part B).

\section{Conclusions}

Field energy balances in natural vegetation and irrigated crops have been used to calibrate and validate the SEBAL algorithm. The satellite images covered the semi-arid region of the LowMiddle São Francisco River basin, North-eastern Brazil, from 2001 to 2007.

The ground data consisted of radiation and energy balances from four field experiments and seven agrometeorological stations. It is one of the first datasets that could be used to validate individual steps of SEBAL since the development of the model.

Most of the expressions required a slight correction for acquiring agreement with the field data. This does not necessarily imply that the use of default equations will lead to inappropriate results of actual evapotranspiration, because SEBAL self-calibrates the value of sensible heat flux.

The coefficients of determination were for: surface albedo $\left(R^{2}=0.90\right)$, daytime integration surface albedo $\left(R^{2}=0.95\right)$, surface temperature $\left(R^{2}=0.93\right)$, apparent emissivity of the atmosphere $\left(R^{2}=0.75\right)$, surface emissivity $\left(R^{2}=0.83\right)$, instantaneous net radiation $\left(R^{2}=0.94\right)$, integration of net radiation $\left(R^{2}=0.80\right)$, surface roughness for momentum transport $\left(R^{2}=0.92\right)$, soil heat flux/net radiation fraction $\left(R^{2}=0.87\right)$, instantaneous soil heat flux $\left(R^{2}=0.80\right)$, instantaneous sensible heat flux $\left(R^{2}=0.83\right)$, integration of evaporative fraction $\left(R^{2}=0.91\right)$, instantaneous latent heat flux $\left(R^{2}=0.93\right)$, integration of actual evapotranspiration $\left(R^{2}=0.91\right)$ and photosynthetically active radiation $\left(R^{2}=0.99\right)$. The apparent emissivity of 
the atmospheric is one of the most problematic parameters, and this has been known for some time.

The direct comparison between field measured latent heat flux and the application of calibrated equations in the SEBAL algorithm to estimate actual evapotranspiration revealed that it is essential to distinguish instantaneous and daily time scales. For instantaneous values it was required to apply the hot and cold pixel calibration for every individual image. For daily scale, the values of the instantaneous evaporative fraction needed to be adjusted.

It was useful to use curves of the ratio of actual to reference evapotranspiration instead the average values of the pixel with the lowest and highest surface temperatures in the calibration processes as this ratio changes during the year.

\section{R E F E R E N C E S}

Ahmad, M.D., Bastiaanssen, W.G.M., 2003. Retrieving soil moisture storage in the unsaturated zone from satellite imagery and bi-annual phreatic surface fluctuations. Irrig. Drain. Syst. 17, 141-161.

Akbari, M., Toomanian, N., Droogers, P., Bastiaanssen, W.G.M., Gieske, A., 2007. Monitoring irrigation performance in Esfahan, Iran, using NOAA satellite imagery. Agric. Water Manage. 88, 99-109.

Allen, R.G., Pereira, L.S., Raes, D., Smith, M., 1998. Crop evapotranspiration. Guidelines for computing crop water requirements. FAO Irrigation and Drainage Paper 56, Rome, Italy, $300 \mathrm{pp}$.

Allen, R.G., Hartogensis, O., de Bruin, H.A.R., 2000. Long-Wave Radiation over Alfafa During the RAPID Field Campaign in Southern Idaho. Research Report, Kimberly, Univ. of Idaho, ID.

Allen, R.G., Tasumi, M., Morse, A., Trezza, R., 2005. A Landsatbased energy balance and evapotranspiration model in Western US rights regulation and planning. Irrig. Drain. Syst. 19, 251-268.

Allen, R.G., Tasumi, M., Trezza, R., 2007a. Satellite-based energy balance for mapping evapotranspiration with internalized calibration (METRIC)-Model. J. Irrig. Drain. Eng. ASCE 133 (4), 380-394.

Allen, R.G., Tasumi, M., Morse, A., Trezza, R., Wright, J., Bastiaanssen, W.G.M., Kramber, W., Lorite, I., Robson, C.W., 2007b. Satellite-based energy balance for mapping evapotranspiration with internalized calibration (METRIC)applications. J. Irrig. Drain. Eng. ASCE 133 (4), 395-405.

Bastiaanssen, W.G.M., 1995. Regionalization of surface flux densities and moisture indicators in composite terrain: a remote sensing approach under clear skies in Mediterranean climates. Ph.D. dissertation, CIP Data Koninklijke Bibliotheek, Den Haag, The Netherlands. 273 pp.

Bastiaansssen, W.G.M., Menenti, M., Feddes, R.A., Holtslag, A.A.M., 1998a. A remote sensing surface energy balance algorithm for land (SEBAL) 1. Formulation. J. Hydrol. 212213, 198-212.

Bastiaansssen, W.G.M., Pelgrum, H., Wang, J., Ma, Y., Moreno, J.F., Roerink, G.J., Wal van der, T., 1998b. A remote sensing surface energy balance algorithm for land (SEBAL). 2. Validation. J. Hydrol. 213-229.

Bastiaanssen, W.G.M., Sakthivadivel, R., Van Dellen Van, A., 1999. Spatially delineating actual and relative evapotranspiration from remote sensing for modelling nonpoint pollutants, in (eds) Corwin, D. et al., Assessment of non-source pollution in the vadose zone, Geophysical
Monograph 108, American Geophysical Union (special issue after joint AGU Chapman/SSSA Outreach Conference Riverside): 179-196.

Bastiaansssen, W.G.M., 2000. SEBAL-based sensible and latent heat fluxes in the irrigated Gediz Basin, Turkey. J. Hydrol. 229, 87-100.

Bastiaanssen, W.G.M., Bandara, K.M.P.S., 2001. Evaporative depletion assessments for irrigated watersheds in Sri Lanka. Irrig. Sci. 21 (1), 1-15.

Bastiaansssen, W.G.M., Brito, R.A.L., Bos, M.G., Souza, R.A., Cavalcanti, E.B., Bakker, M.M., 2001. Low cost satellite data for monthly irrigation performance monitoring: benchmarks from Nilo Coelho, Brazil. Irrig. Drain. Syst. 15, 53-79.

Bastiaanssen, W.G.M., Ahmed, M.-ud-D., Chemin, Y., 2002. Sattellite surveillance of evaporative depletion across the Indus Basin. Water Resour. Res. 38, 1273-1282.

Bastianssen, G.M.W., Chandrapala, L., 2003. Water balance variability across Sri Lanka for assessing agricultural and environmental water use. Agric. Water Manage. 58 (2), 171-192.

Bastiaanssen, W.G.M., Harshadeep, N., 2005. Managing scarce water resources in Asia: the nature of the problem and can remote sensing help? Irrig. Drain. Syst. 19 (3-4), 269-284.

Bastiaanssen, W.G.M., Noordman, E.J.M., Pelgrum, H., Davids, G., Allen, R.G., 2005. SEBAL for spatially distributed ET under actual management and growing conditions. J. Irrig. Drain. Eng. 131, 85-93.

Bastiaanssen, W.G.M., Pelgrum, H., Soppe, R.W.O., Allen, R.G., Thoreson, B.P., Teixeira, A.H. de C., 2008. Thermal infrared technology for local and regional scale irrigation analysis in horticultural systems. ISHS Acta Hort. 792.In: Proc. Vth IS on Irrigation of Horticultural Crops.

Bruin de, H.A.R., 1987. From Penman to Makkink. In: Hooghart, J.C. (Ed.), Proceedings and Information: TNO Commitee on Hydrological, vol. 39, Gravennhage, The Netherlands, pp. 5-31.

Bruin de, H.A.R., Stricker, J.N.M., 2000. Evaporation of grass under non-restricted soil moisture conditions. Hydrol. Sci. J. 45 (3), 391-406.

Businger, J.A., Wyngaard, J.C., Izumi, Y., Bradley, E.F., 1971. Fluxprofile relationships in the atmospheric surface layer. J. Atm. Sci. 28, 189-191.

Chemin, Y., Platonov, A., UI-Hassan, Abdullaev, I., 2004. Using remote sensing data for water depletion assessment at administrative and irrigation-system levels: case study of the Ferghana Province of Uzbekistan. Agric. Water Manage. 64, 183-196.

Choudhury, B.J., 1989. Monitoring global land surface using Nimbus-7 $37 \mathrm{GHz}$ data. Theory and examples. Int. J. Rem. Sens. 10, 1579-1605.

Cleugh, H.A., Dunin, F.X., 1995. Modeling sensible heat fluxes from a wheat canopy: evaluation of resistance energy balance model. J. Hydrol. 164, 127-152.

Cleugh, H.A., Leuning, R., Mu, Q., Running, S.W., 2007. Regional evaporation estimates from flux tower and MODIS satellite data. Rem. Sens. Envir. 106, 285-304.

Clothier, B.E., Clawson, K.L., Pinter, P.J., Moran, M.S., Reginato, R.J., Jackson, R.D., 1986. Estimating of soil heat flux from net radiation during the growth of alfafa. Agric. For. Meteorol. 37, 319-379.

Courault, D., Seguin, B., Olioso, A., 2005. Review on estimation of evapotranspiration from remote sensing data: from empirical to numerical modeling approaches. Irrig. Drain. Syst. 19, 223-249.

Duchemin, J., Hadria, R., Er-Raki, S., Boulet, G., Maisongrande, P., Chehbouni, A., Escadafal, R., Ezzahar, J., Hoedjes, J., Karroui, H., Khabba, S., Mougenot, B., Olioso, A., Rodriguez, J.-C., Simonneaux, V., 2006. Monitoring wheat phenology 
and irrigation in Central Morocco: on the use of relationship between evapotranspiration, crops coefficients, leaf area index and remotely-sensed vegetation indices. Agric. Water Manage. 79, 1-27.

El-Magd, I.A., Tanton, T.W., 2005. Remote sensing and GIS for estimation of irrigation crop water demand. Int. J. Rem. Sens. 26 (10), 2359-2370.

Farah, H.O., Bastiaanssen, W.G.M., 2001. Impact of spatial variations of land surface parameters on regional evaporation: a case study with remote sensing data. Hydrol. Process. 15 (9), 1585-1607.

Franks, S.W., Beven, K., 1999. Conditioning a multiple patch SVAT model using uncertain time-space estimates of latent heat fluxes as inferred from remotely sensed data. Water Resour. Res. 35, 2751-2761.

Froin, R., Pinker, R.T., 1995. Estimating photosynthetically radiation (PAR) at the earth's surface from satellite observations. Rem. Sens. Envir. 51, 98-107.

Immerzeel, W.W., Gaur, A., Zwart, S.J., 2008. Integrating remote sensing and a process-based hydrological model to evaluate water use and productivity in a South Indian catchment. Agric. Water Manage. 95 (1), 11-24.

Jackson, R.D., Reginato, R.J., Idso, S.B., 1977. Wheat canopy temperatures; a practical tool for evaluating water requirements. Water Resour. Res. 13, 651-656.

Kalma, J.D., Jupp, D.L.B., 1990. Estimating evaporation from pasture using infrared thermometry: evaluation of one layer resistance model. Agric. For. Meteorol. 51, 223-246.

Koloskov, G., Mukhamejanov, Kh., Tanton, T.W., 2007. MoninObukhov length as a cornerstone of the SEBAL calculations of evapotranspiration. J. Hydrol. 335 (1-2), 170-179.

Kustas, W.P., Norman, J.M., 1996. Use of remote sensing for evapotranspiration monitoring over land surface. IAHS Hydrol. Sci. J. 4, 495-516.

Kustas, W.P., Li, F., Jackson, T.J., Prueger, J.H., MacPherson, J.I., Wolde, M., 2004. Effects of remote sensing pixel resolution on modeled energy flux variability of croplands in Iowa. Rem. Sens. Envir. 92 (4), 535-547.

Landsat 7 Science Data User Handbook, Chapter 11, 2002-Data Products http://ltpwww.gsfc.nasa.gov/IAS/handbook/ handbook_htmls/chapter11/chapter11.html.

Leuning, R., Cleugh, H.A., Zegelin, S.J., Hughes, D., 2005. Carbon and water fluxes over a temperate Eucalyptus forest and a tropical wet/dry savanna in Australia: measurements and comparison with MODIS remote sensing estimates. Agric. For. Meteorol. 129, 151-173.

Markham, B.L., Barker, J.L., 1986. Landsat MSS and TM Postcalibration Dynamic Ranges, Exoatmospheric Reflectances and At-Satellite Temperatures: EOSAT Landsat Technical Notes, vol. 1, pp. 3-8.

McCabe, M., Wood, E.F., 2006. Scale influences on the remote estimation of evapotranspiration using multiple satellite sensors. Rem. Sens. Envir. 105, 271-285.

Menenti, M., Bastiaanssen, W.G.M., Van Eick, D., 1989. Determination of hemispheric reflectance with thematic mapper data. Rem. Sens. Envir. 28, 327-337.

Moran, M.S., Maas, S.J., Pinter, P.J., 1995. Combining remote sensing and modeling for estimating surface evaporation and biomass production. Rem. Sens. Rev. 12, 335-353.

Nagler, P.L., Scott, R.L., Westenburg, C., Cleverly, J.R., Glenn, E.P., Huete, A.R., 2005. Evapotranspiration on western U.S. rivers estimated using the Enhanced Vegetation Index from
MODIS and data from eddy covariance and Bowen ratio flux towers. Rem. Sens. Envir. 97, 337-351.

Nagler, P.L., Glenn, E.P., Kim, H., Emmerich, W., Scott, R.L., Huxman, T.E., Huete, A.H., 2007. Relationship between evapotranspiration and precipitation pulses in a semiarid rangeland estimated by moisture flux towers and MODIS vegetation indices. J. Arid Env. 70 (3), 443-462.

Pelgrum, H., Bastiaanssen, W.G.M., 1996. An inter comparison of techniques to determine the area-averaged latent heat flux from individual in situ observations: a remote sensing approach using the European Field Experiment in a Desertification-Threatened Area delta. Water Resour. Res. 9, 2775-2786.

Schmugge, T., Becker, F., 1991. In: Andre, J.C., Schmugge, T. (Eds.), Remote Sensing Observations of the Monitoring of Land Surface Fluxes and Water Budget in Determination of Land Surface Fluxes during HAPEX. Springer Verlag, pp. 337-347.

Schmugge, T., Hook, S.l., CoII, C., 1998. Recovering surface temperature and emissivity from thermal infrared multispectral scanner data. Rem. Sens. Envir. 65, 121-131.

Smith, R., G.C., Barrs, H.D., Meyer, W.S., 1989. Evaporation from irrigated wheat estimated using radiative surface temperature: an operational approach. Agric. For. Meteorol. 48, 331-344.

Steduto, P., Kijne, J.W., Hanjra, M.A., Binibraban, P.S., 2007. Pathways for increasing agricultural water productivity. In: Molden, D. (Ed.), Water for Food, Water for Life: A Comprehensive Assessment of Water Management in Agriculture. International Water Management Institute, Earthscan, and Colombo, London, pp. 279-310.

Tasumi, M., Allen, R.G., 2007. Satellite-based ET mapping to assess variation in ET with timing of crop development. Agric. Water Manage. 88, 54-62.

Teixeira, A.H. de C., Bastiaanssen, W.G.M., Bassoi, L.H., 2007. Crop water parameters of irrigated wine and table grapes to support water productivity analysis in Sao Francisco River basin, Brazil. Agric. Water Manage. 94, 31-42.

Teixeira, A.H. de C., Bastiaanssen, W.G.M., Moura, M.S.B., Soares, J.M., Ahmad, M-ud-D, Bos, M.G., 2008a. Energy and water balance measurements for water productivity analysis in irrigated mango trees, northeast Brazil. Agric. For. Meteorol. 148, 1524-1537.

Teixeira, A.H. de C., Bastiaanssen, W.G.M., Ahmad, M.D., Moura, M.S.B., Bos, M.G., 2008b. Analysis of energy fluxes and vegetation-atmosphere parameters in irrigated and natural ecosystems of semi-arid Brazil. J. Hydrol 362, 110-127.

Troufleau, D., Lhomme, J.-P., Monteny, B., Vidal, A., 1997. Sensible heat flux and radiometric surface temperature over sparse sahelian vegetation: is the $k B-1$ a relevant parameter. J. Hydrol. 189, 815-838.

Van der Griend, A.A., Owe, M., 1993. Determination of microwave vegetation optical depth and single scattering albedo from large scale moisture and Nimbus/SMMR satellite observations. Int. J. Rem. Sens. 14 (10), 1975-1996.

Wang, J., Bastiaanssen, W.G.M., Ma, Y., Pelgrum, H., 1998. Aggregation of land surface parameters in the oasis-desert systems of Northwest China. Hydrol. Process. 12, 2133-2147.

Wylie, B., Johnson, D., Laca, E., Saliendra, N., Gilmanov, T., Reed, B., Tieszen, L., Worstell, B., 2003. Calibration of remotely sensed, coarse resolution NDVI to $\mathrm{CO}_{2}$ fluxes in a sagebrush-steppe ecosystem. Rem. Sens. Envir. 85s, 243-255. 